\title{
Análise das formas de relevo do município de Cacequi - RS
}

\author{
Analysis of relief forms of the Cacequi municipality - RS \\ Lucas Krein Rademann ${ }^{1}$, Romario Trentin ${ }^{2}$, Luis Eduardo de Souza Robaina ${ }^{3}$ \\ ${ }^{1}$ Graduando, Departamento de Geociências, Universidade Federal de Santa Maria, Santa Maria, Brasil \\ lucasrademann@yahoo.com \\ ${ }^{2}$ Doutor, Departamento de Geociências, Universidade Federal de Santa Maria, Santa Maria, Brasil \\ romario.trentin@gmail.com \\ ${ }^{3}$ Doutor, Departamento de Geociências, Universidade Federal de Santa Maria, Santa Maria, Brasil \\ lesrobaina@yahoo.com.br
}

\begin{abstract}
Resumo
O relevo é moldado por diversos processos naturais e antrópicos. Estes processos condicionam o desenvolvimento de diversas formas de relevo. As características destas formas proporcionam limitações e aptidões para o uso do terreno. Sendo assim, o presente trabalho tem como objetivo analisar as formas do relevo, de Cacequi, município da região Oeste do estado do Rio Grande do Sul. Para a elaboração das análises morfométricas foi utilizado o SIG ArcGIS 10.1, com as ferramentas topo to raster, slope e spatial analyst. Sua hidrografia foi analisada conforme Strahler (1952). Foram utilizadas 5 classes para a elaboração do mapa hipsométrico de Cacequi de acordo com a altitude média do terreno do município. Ainda para a análise da declividade foram utilizadas 4 classes definidas pelo IPT menores que $2 \%$, de 2 á $5 \%$, de 5 á $15 \%$ e mais de 15\%. As formas de relevo foram divididas em colinas, colinas suaves, morrotes e planícies aluviais. Cacequi possui altitude baixa e pequena variação altimétrica, consequentemente, também declividades baixas, caracterizando relevo homogêneo representado pelos valores próximos de comprimento médio das vertentes em suas sub-bacias com o predomínio de colinas e planícies. $O$ estudo de relevo é informação básica para compreender os processos superficiais.
\end{abstract}

Palavras-chave: Formas de relevo. Oeste do Rio Grande do Sul. Morfometria

\begin{abstract}
The landscape is shaped by various natural and anthropogenic processes. These processes affect the development of various forms of relief. The characteristics of these forms provide limitations and skills for the use of the land. Thus, this study aims to analyze the forms of relief, of Cacequi, municipality of western state of Rio Grande do Sul region. In developing the hydrographic maps, slope, hypsometry and landforms was used GIS ArcGIS 10.1, using topo to raster, slope e spatial analyst outil. Its hydrography was analyzed and prioritized according to Strahler (1952). 5 classes were used for the preparation of topographic map of Cacequi according to the average altitude of the municipality's land. Even for the analysis of the slope were used 4-defined classes IPT smaller than $2 \%$, from 2 to 5\%, 5 to 15\% and more than 15\%. The landforms were divided into hills, rolling hills, buttles and floodplains. Cacequi has low altitude and small altimetry variation therefore also lower slopes, featuring homogeneous relief represented by values close to average length of the strands in their sub-basins with the predominance of hills and plains. The study of relief, shown to be important to understand surface process.
\end{abstract}

Keywords: Relief forms. West of the Rio Grande do Sul. Morphometry 


\section{Introdução}

O relevo é moldado por diversos processos naturais e antrópicos, e de acordo com estes processos, vai tomando diversas formas, contudo cada uma delas tem suas características e proporcionam limitações e aptidões para o uso do terreno, sendo assim, é importante analisar as formas e feições do relevo para entender os processos da área estudada.

O estudo e análise do relevo, suas características e sua composição são importantes para um bom entendimento de uma área. Frente a isto, têm surgido diversos estudos de relevo enquadrados em análises morfométricas facilitando o entendimento das dinâmicas superficiais dos locais estudados tendo em vista o planejamento e gestão dos mesmos.

Segundo De Nardin e Robaina (2005) “a problemática ambiental tornou-se evidente a partir da transformação do meio ambiente, decorrente do acelerado processo de ocupação do espaço e apropriação dos recursos naturais pelo homem. Nessa visão, os estudos ambientais fazem-se necessários para um melhor planejamento e manejo das áreas".

O estudo do relevo é de grande importância para a compreensão dos processos da natureza e, através destes estudos se consegue uma análise mais detalhada da região para o planejamento da mesma, classificando o terreno de acordo com as formas e potencialidades.

Destaca Menezes et al (2013) que, "o estudo das formas de relevo se apresenta como objeto fundamental da Geomorfologia, tanto nos aspectos de gênese como evolução destas formas. Embora o relevo, numa rápida observação, pareça ser um componente estático do meio, está em constante processo de evolução, com velocidades variadas, interagindo, a todo instante, com os demais componentes da paisagem".

Ainda Soares e Souza (2012) destacam que "a análise morfométrica por meio de características geomorfológicas associadas ao relevo e á rede de drenagem, possibilita a identificação de suas características gerais. Essas medidas podem servir como um referencial para o planejamento ambiental e proposta de reestruturação regional, com o intuito de auxiliar a tomada de decisão de projetos envolvendo o uso de recursos físicos na região."

Destaca-se nesta área o Laboratório de Geologia Ambiental (LAGEOLAM/UFSM), que vem desenvolvendo estudos geoambientais e geomorfológicos no oeste do Rio Grande do sul, tendo destaque para Trentin e Robaina (2006), com o Mapeamento Morfolitológico da Bacia Hidrográfica do Rio Itú; De Nardin e Robaina (2005), com o mapeamento de unidades de relevo para a Bacia Hidrográfica do Arroio Miracatú/RS; também Baratto e Trentin (2012), com a análise das unidades de relevo da Bacia Hidrográfica do Arroio Puitã/RS.

Assim surgem como parte do estudo do relevo as formas do relevo, que se faz importante para compreendermos os processos que originaram o terreno atual e os que estão moldando o relevo nos dias de hoje. Observa-se que as formas de relevo são resultantes dos processos atuantes e o estudo destes proporciona um entendimento geomorfológico da região.

Sendo assim, o presente trabalho tem como objetivo analisar e interpretar dados hipsométricos, de declividade, morfométricos, hidrográficos e também as formas

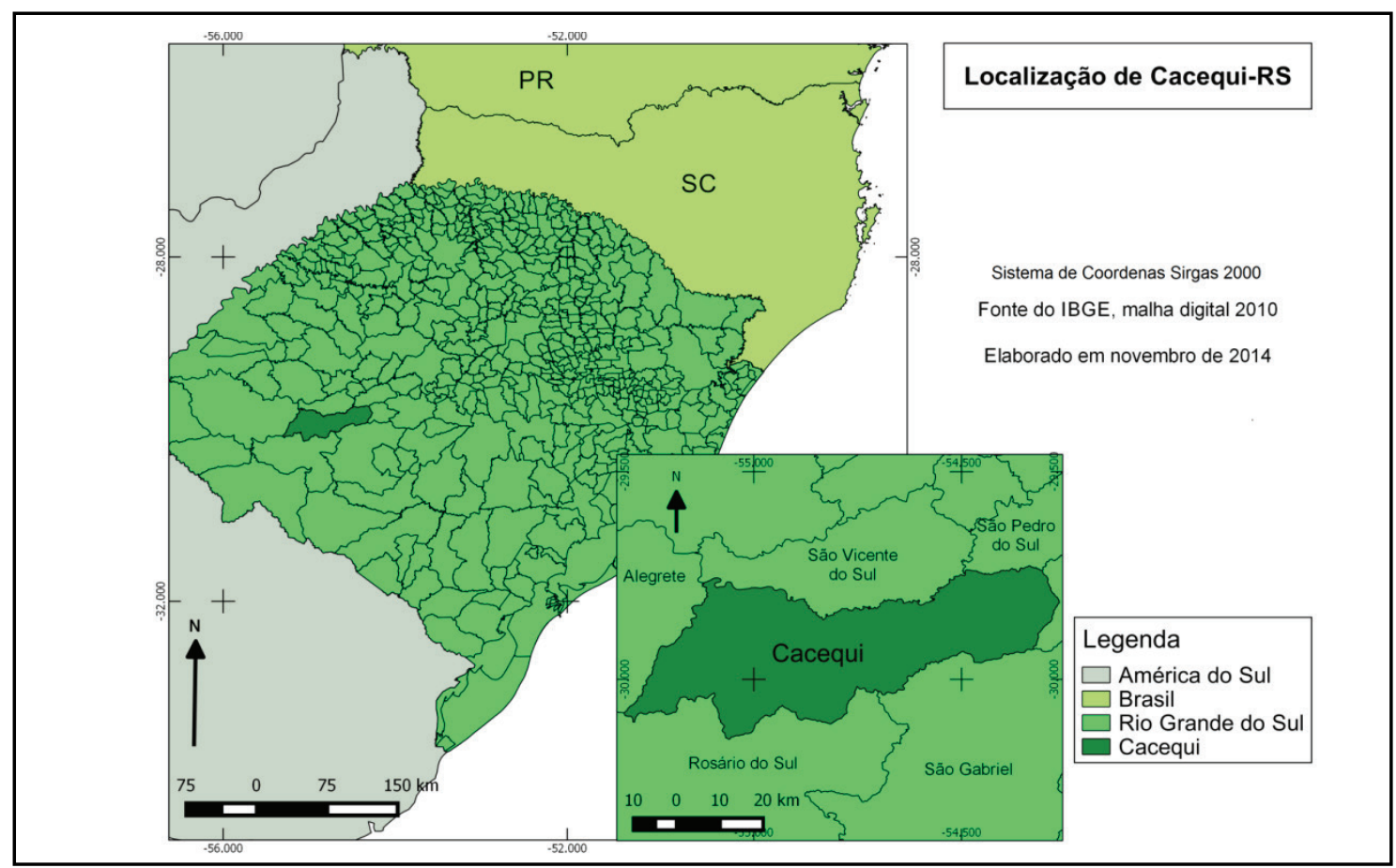

Figura 1 - Mapa de Localização do município de Cacequi

Org: Os Autores, 2015 
do relevo. Através desta análise, foi feita uma relação dos aspectos do relevo de Cacequi, sua caracterização e também um estudo de sua espacialização no município de Cacequi.

O município de Cacequi possui 2338 km², e está localizado na região central do estado do Rio Grande do Sul (Figura 1), estando em sua quase totalidade do terreno na depressão periférica sul-rio-grandense. Cacequi está incluso na bacia hidrográfica do Rio Ibicuí, e possui 10 sub-bacias de ordem 3 ou maiores, segundo a classificação de Strahler (1952). Faz limite com os municípios de São Vicente do Sul ao Norte, São Pedro do Sul a Nordeste, Dilermando de Aguiar a Leste, Rosário do Sul a Sul e São Gabriel a Sudeste.

\section{Metodologia}

Para a elaboração dos mapas presentes no estudo das formas de relevo de Cacequi, foi utilizado o Sistema de Informação Geográfica (SIG) ArcGIS 10.1, desenvolvido pela ESRI. Utilizou-se de cartas topográficas do Exército Brasileiro na escala 1:50. 000 para a digitalização das curvas de nível e através destas, foi gerado o mapa hipsométrico, hidrográfico, clinográfico e o mapa das formas de relevo do município.

Para a definição do limite do município de Cacequi foi utilizado o banco de dados do IBGE na sua malha digital do ano de 2010 e então, através do SIG e da base cartográfica das cartas topográficas em escala 1:50.000, foi melhorado o limite municipal, seguindo as feições estabelecidas na lei municipal que estabelece as linhas limítrofes do município (drenagens, estradas), figura 2.

As sub-bacias hidrográficas foram subdivididas seguindo a hierarquia igual ou maior que terceira ordem, segundo a classificação de Strahler (1952), e delimitadas de acordo com o seu divisor topográfico.

Após a digitalização das curvas de nível e dos pontos cotados do município, utilizou-se a ferramenta Topo to Raster do ArcGIS 10.1 para a elaboração do mapa hipsométrico da área de estudo. Estabeleceram-se então cinco classes para altitude do município de acordo com a variação média do relevo, sendo estas menores de 80 metros, de 80 até 110 metros, altitudes entre 110 e 140 metros, de 140 a 170 metros e também altitudes superiores a 170 metros.

Com o mesmo banco de dados, e através da ferramenta Slope, do mesmo SIG, foi gerado o mapa de declividade (em porcentagens) de Cacequi. Para o estudo de declividade utilizou-se de dados definidos pelo Instituto de Pesquisas Tecnológicas do estado de São Paulo IPT (1981) e apresentado por Trentin e Robaina (2006), 2\%, $5 \%$ e $15 \%$ em que as áreas com declividade de $2 \%$ são muito planas e presente o processo de deposição, áreas de declividade de 5\% são áreas de transição entre processos de deposição e meteorização, e as declividades de $15 \%$ representam áreas propícias para movimento de massas e limite para uso de maquinário agrícola. Sendo assim, as declividades de Cacequi foram divididas em quatro classes, sendo estas as menores que $2 \%$, entre 2 e $5 \%$, valores de 5 a $15 \%$ e superiores a $15 \%$.

Com o auxílio da ferramenta spatial analyst do ArcGis 10.1 foram obtidos dados das sub-bacias de Cacequi que permitiram os cálculos de Densidade de Drenagem, Comprimento dos rios, e Índice de Circularidade.

A Densidade de Drenagem foi calculada através da expressão, tal que, Dd é densidade de drenagem, Lt é o comprimento total dos canais e A é a área, sendo que densidade de drenagem é a relação entre o comprimento

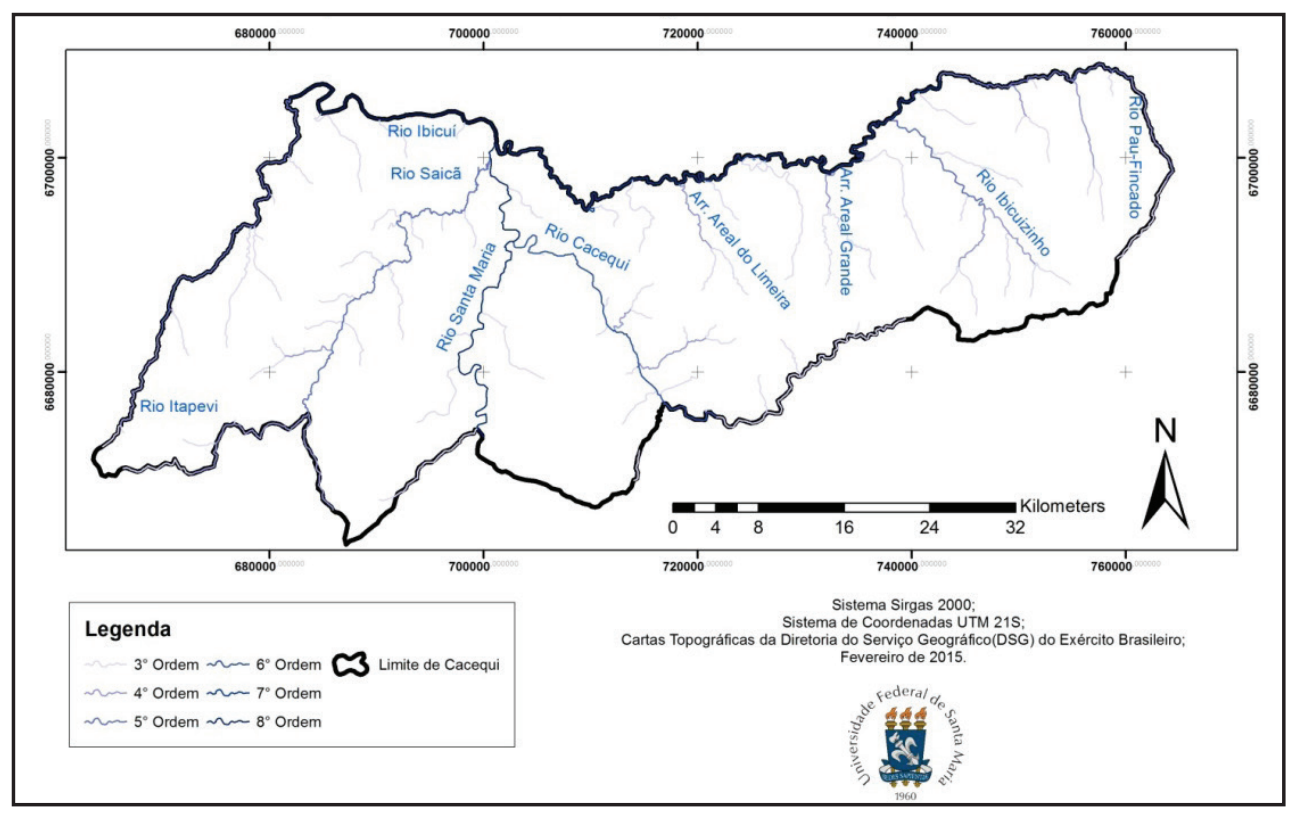

Figura 2 - Mapa do limite municipal atualizado com as principais drenagens de Cacequi

Org: Os Autores, 2015 
total dos segmentos de canais pela área de estudo.

Para o cálculo de Índice de Circularidade, que é a relação entre a área de um círculo de perímetro igual da bacia e da área da bacia referida, tal que se utilizou a fórmula em que Ic é Índice de Circularidade, Ac representa a área do circulo de perímetro igual da bacia e A a área da bacia hidrográfica estudada.

$\mathrm{Na}$ análise do Comprimento Médio dos canais, que é a média dos canais de cada ordem, utilizou-se da expressão, em que Lm é o comprimento médio dos canais, Lt representa o comprimento total dos canais e $\mathrm{N}$ o número total de canais.

Para a análise do padrão de drenagem, foi utilizado o critério estabelecido por Christofoletti (1974) sendo que "os padrões de drenagem referem-se ao arranjo espacial dos cursos fluviais, que podem ser influenciados em sua atividade morfogenética pela natureza e deposição das camadas rochosas, pela resistência litológica variável, pelas diferenças de declividade e pela evolução geomorfológica da região".

Na elaboração do mapa de feições de relevo, foi tomado como base os mapas de declividade e hipsométrico, analisando-se estes mapas foram discriminados quatro tipos de feições diferentes no município de Cacequi, tendo como base a metodologia do IPT. Sendo estas feições morrotes, que são áreas do relevo em que há uma diferença altimétrica grande em relação ao terreno e com declividades próximas a 15\%; colinas, definidas por feições pouco mais onduladas no relevo, e com altitude e declividades médias; colinas suaves, são feições levemente onduladas, com baixas altitudes e declividades; planícies, que são áreas onde o relevo se apresenta de forma bastante plana, com declividades inferiores a $2 \%$ e altitudes bastante baixas.

Para o comprimento médio das vertentes, foram medidas quinze vertentes de cada sub-bacia hidrográfica
Tabela 1 - Classificação das formas de relevo segundo IPT

\begin{tabular}{ccc}
\hline Classe & & $\begin{array}{c}\text { Amplitude } \\
\text { altimétrica }\end{array}$ \\
Áreas Planas & & \\
associada aos & $<2 \%$ & $<100 \mathrm{~m}$ \\
Cursos da Água & & \\
Colin. Lev. Ond. & $2 \%-5 \%$ & $<100 \mathrm{~m}$ \\
Col. Ond. & $5 \%-15 \%$ & $<100 \mathrm{~m}$ \\
Morrotes & $>15 \%$ & $<100 \mathrm{~m}$ \\
\hline
\end{tabular}

Org: Os Autores 2015

do município, sendo cinco em cada setor da bacia, alto curso, médio e baixo curso da bacia. Através dos dados coletados, estabeleceu-se a média do comprimento das vertentes dentro de cada bacia, e foi calculado o padrão de desvio de todo o município, através da expressão em que Pd é Padrão de Desvio e Mm representa a média do município.

Os gráficos e tabelas presentes na área de estudo realizado foram elaborados através do Excel 2010, com o auxílio de dados gerados no programa ArcGis 10.1.

\section{Resultados}

\subsection{Análise Hidrográfica}

Para o estudo da hidrografia o município de Cacequi foi dividido em sub-bacias hidrográficas, todas elas de ordem maior ou igual a três, resultando assim em 9 sub-bacias mais os afluentes diretos do Rio Ibicuí, como representa a Figura 3.

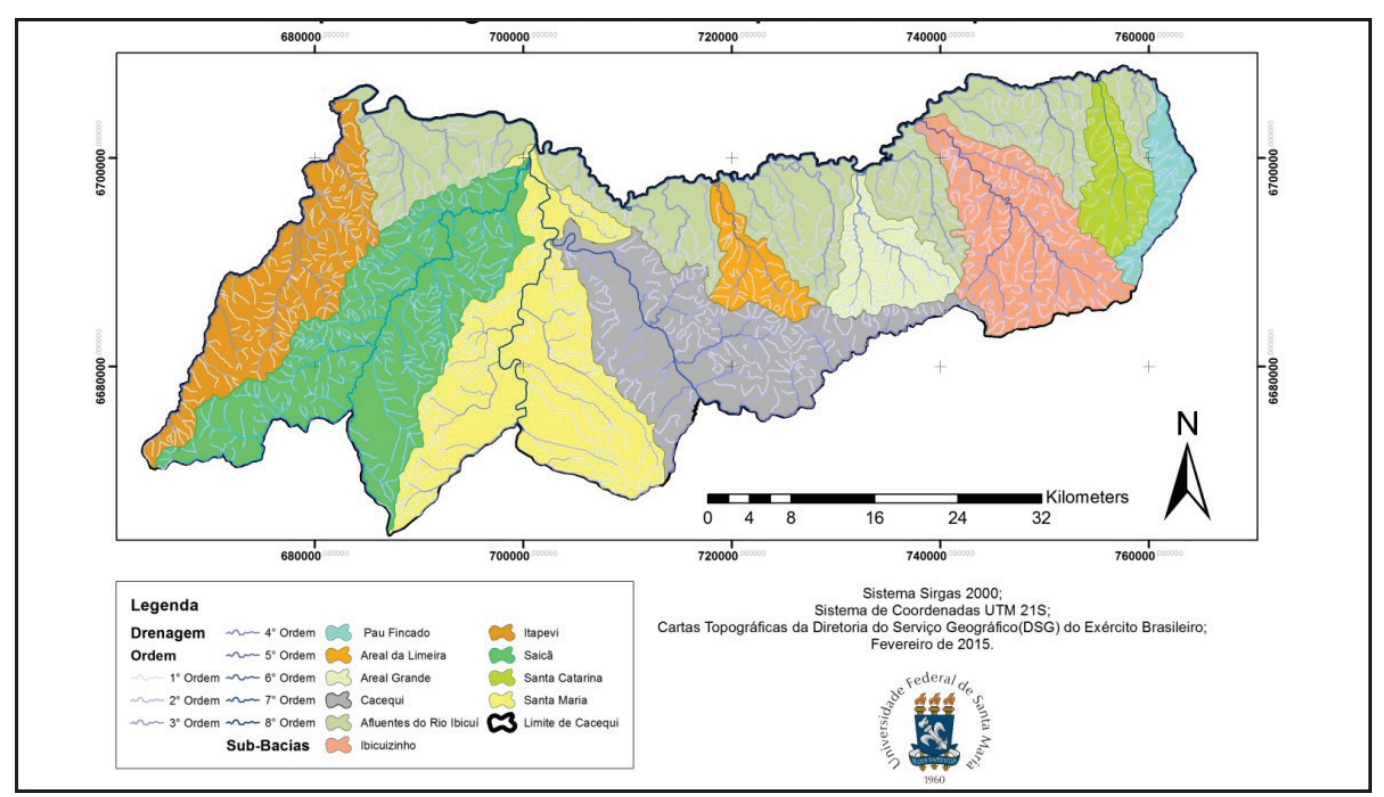

Figura 3 - Mapa da Hidrografia do município de Cacequi - RS

Org: Os Autores, 2015 
Tabela 2 - Sub-bacias do município de Cacequi

\begin{tabular}{|c|c|c|c|c|}
\hline Nome da Bacia & $\begin{array}{l}\text { Área } \\
\left(\mathbf{k m}^{2}\right)\end{array}$ & $\begin{array}{l}\text { Comprimento total } \\
\text { dos rios }(\mathrm{km})\end{array}$ & Ordem & $\begin{array}{c}\text { Densidade de } \\
\text { drenagem } \mathrm{km} / \mathrm{km}^{2}\end{array}$ \\
\hline Areal Grande & 94,09 & 124,07 & 4 & 1,31 \\
\hline Areal do Limeira & 60,7 & 86,8 & 4 & 1,43 \\
\hline Cacequi & 325,36 & 384,22 & 6 & 1,18 \\
\hline Ibicuí & 513,77 & 675,35 & 8 & 1,31 \\
\hline Ibicuízinho & 218,2 & 322,1 & 5 & 1,47 \\
\hline Itapevi & 224,89 & 357,22 & 5 & 1,58 \\
\hline Pau-Fincado & 43,86 & 72,17 & 4 & 1,64 \\
\hline Saicã & 402,25 & 523,89 & 5 & 1,3 \\
\hline Santa Catarina & 72,17 & 97,92 & 4 & 1,35 \\
\hline Santa Maria & 383,19 & 381,63 & 8 & 0,99 \\
\hline
\end{tabular}

Org: Os Autores, 2015

Tabela 3 - Índice de Circularidade das sub-bacias de Cacequi;

\begin{tabular}{cc}
\hline Nome da Bacia & Índice de Circularidade \\
Areal Grande & 0,44 \\
Areal do Limeira & 0,33 \\
Cacequi & 0,19 \\
Ibicuí & 0 \\
Ibicuízinho & 0,41 \\
Itapevi & 0 \\
Pau-Fincado & 0 \\
Saicã & 0,26 \\
Santa Catarina & 0,41 \\
Santa Maria & 0,22 \\
\hline
\end{tabular}

Org: Os Autores 2015

Ao total, Cacequi possui 1554 segmentos de canais de ordem até oito, possuindo 3.072,02 km de comprimento, portanto o comprimento médio dos segmentos de canais do município é de 1,97 km.

Observa-se então que o padrão de drenagem do município é paralelo-dendrítico, característicos de áreas sedimentares, em que a drenagem se assemelha à configuração de uma árvore, onde os canais tributários distribuem-se em todas as direções formando ramos chegando ao canal principal que se assemelha a um tronco, ainda que em alguns casos os tributários tenham uma distribuição paralela até confluírem ao canal principal. Entretanto, em algumas porções, a Nordeste do município onde há maiores altitudes, há algumas drenagens com padrão retangular formando ângulos de $90^{\circ}$ com os afluentes, característico de região com controle estrutural.

A Tabela 2 mostra os dados das sub-bacias hidrográficas do município, destacando a densidade de drenagem, que é um dado que representa quantos quilômetros de segmentos de canal há por quilômetro quadrado de área, assim representa a capacidade do solo de absorção da água ou a capacidade do solo de escoá-la.

Analisando a tabela, vemos que o município tem algumas sub-bacias com densidades de drenagem superiores a $1,5 \mathrm{~km} / \mathrm{km}^{2}$ como as bacias dos rios Pau-Fincado e Itapevi e menores que $1,3 \mathrm{~km} / \mathrm{km}^{2}$ como as bacias do rio Santa Maria e do Saicã. São valores considerados baixos, porque segundo Villela e Mattos (1975) "se a densidade de drenagem for maior que $3,5 \mathrm{~km} / \mathrm{km}^{2}$ é considerada excepcionalmente bem drenada, e se for 
inferior a $0,5 \mathrm{~km} / \mathrm{km}^{2}$ é uma área de drenagem pobre". Considerando que Cacequi possui uma Densidade de Drenagem média de $1,35 \mathrm{~km} / \mathrm{km}^{2}$ podemos dizer que é uma drenagem média ou quase pobre, o que pode ser justificado pela litologia local, sendo que é constituída por arenitos que facilitam a infiltração da água no solo, tendo assim menos canais superficiais.

Quanto ao Índice de Circularidade, todas as sub-bacias têm valores semelhantes, sendo que todas são valores menores que 0,5 (Tabela 3 ). Portanto, considerando que se o Índice de Circularidade for 1 a bacia é redonda, conclui-se que as bacias hidrográficas de Cacequi são mais estreitas e alongadas, então a água vinda dos afluentes chega ao canal principal em seções diferentes do rio, dificultando assim o extravasamento do canal principal.

\subsection{Análise Hipsométrica}

O município de Cacequi apresenta uma amplitude altimétrica pequena, com a sua menor cota com valor de 72 metros próximo à foz do Rio Cacequi (Figura 3), junto ao Rio Ibicuí e seu ponto mais alto de 217 metros localizado na região Sudoeste do município próximo ao Arroio Saicã, tendo uma amplitude altimétrica de apenas 145 metros.

Na Figura 4 está representado o mapa hipsométrico de Cacequi com cinco classes de altitude de acordo com a amplitude altimétrica média do município sendo estas classes: menor de 80 metros de altitude, entre 80 e 110 metros, altitudes entre 110 e 140 metros, entre 140 e 170 metros e valores altimétricos superiores a 170 metros. A
Figura 5 apresenta as áreas das classes hipsométricas.

Observa-se que o município de Cacequi possui em $42,4 \%$ do seu terreno altitudes de $80-110$ metros, constituindo a maior parte do terreno do município com $991,48 \mathrm{~km}^{2}$, localizado principalmente em áreas próximas aos principais rios, como o Ibicuí, Cacequi, Santa Maria e Itapevi.

O município tem ainda, 30,85\% de seu território em altitudes de 110 á 140 metros de altitude, presentes geralmente em interflúvios, separando as drenagens, representando assim uma área total de $721,35 \mathrm{~km}^{2}$.

Em menores áreas, as altitudes de 140 - 170 metros com $15,67 \%$ do terreno, ou seja, $366,55 \mathrm{~km}^{2}$ se apresentam nos locais mais altos do município, principalmente no setor Leste do município e no extremo Oeste.

As áreas menores que 80 metros representam $9,6 \%$ do terreno, com 225,19 km² e localizam-se nas várzeas dos principais rios do município, sendo eles os rios Ibicuí, Cacequi e Santa Maria.

Com apenas 1,6\% do terreno, as altitudes de 170 metros ou mais, se localizam principalmente no divisor de águas das bacias hidrográficas do município.

Observa-se assim, que grande parte do município de Cacequi está entre as altitudes de 80 á 140 metros. São áreas bastante baixas, e com bastante homogeneidade no terreno, características da litologia local. Estas áreas baixas estão geralmente associadas a cursos d'água e favorecem o desenvolvimento de atividades agrícolas como o cultivo de arroz irrigado e também a grande disponibilidade de água nestas áreas com pastagens sadias torna possível e comum à pecuária no município.

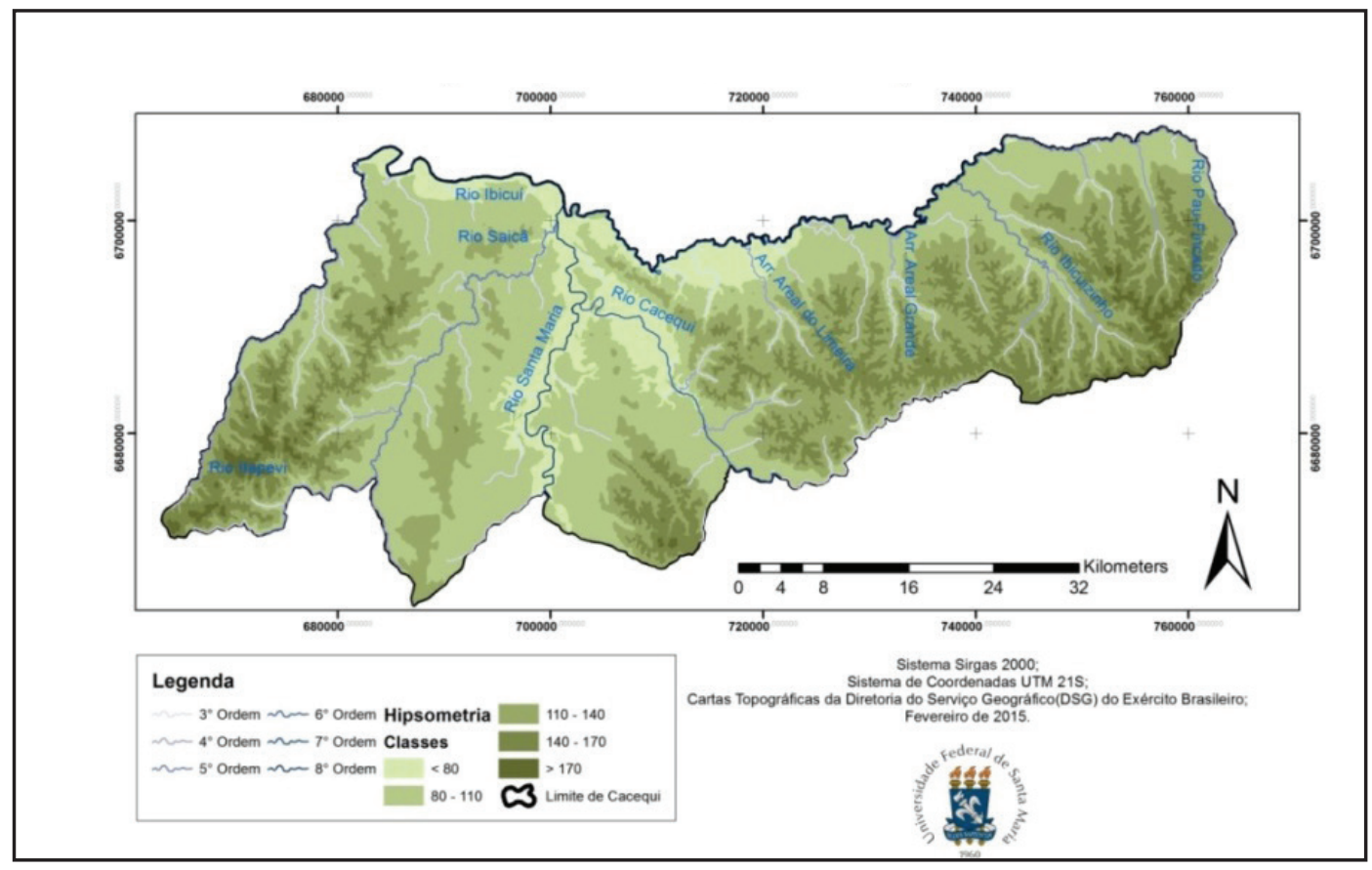

Figura 4 - Mapa Hipsométrico de Cacequi

Org: Os autores, 2015 


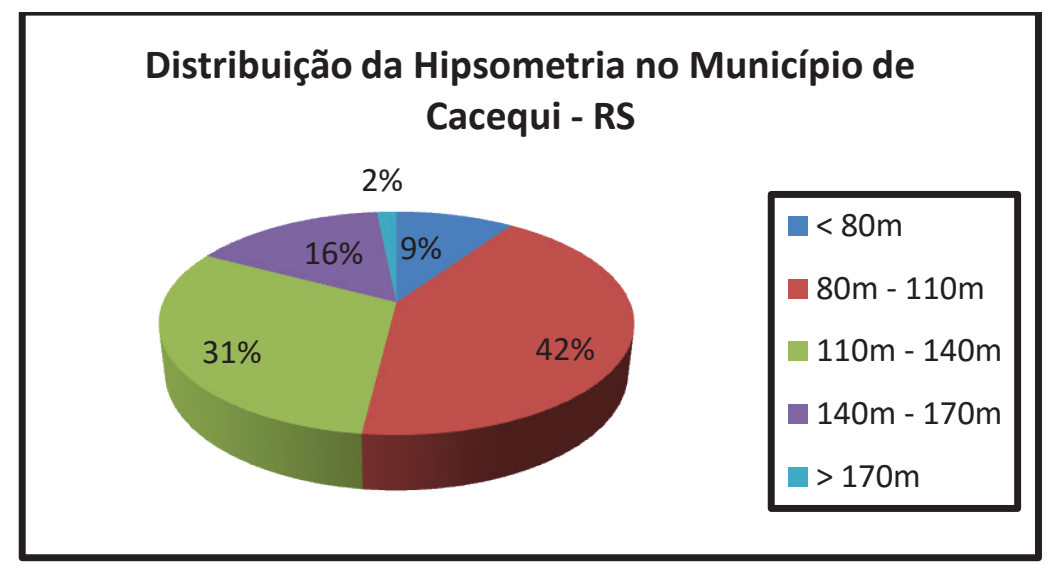

Figura 5 - Gráfico de Distribuição, por área, da hipsometria no terreno do município de Cacequi Org: Os Autores 2015

\subsection{Análise de Declividade das Vertentes}

Segundo De Nardin e Robaina (2005) “A análise das declividades das vertentes torna-se importante no estudo das potencialidades da área relacionadas ao uso e ocupação". Então, se estabeleceu quatro classes para se analisar a declividade no município de Cacequi, declividades menores que $2 \%$, entre 2 e $5 \%$, também de 5 á $15 \%$ e maiores que $15 \%$, conforme representado no mapa a seguir.

O município de Cacequi tem em sua maior parte do terreno declividades menores de 2\%, com área de 1360,57 $\mathrm{km}^{2}$ representando $58 \%$ do município. Esta declividade é característica de ambientes sedimentares e Cacequi está localizado na depressão central do estado do Rio
Grande do Sul, um compartimento geomorfológico de ambiente sedimentar. As áreas com declividade menor que $2 \%$ estão associadas às áreas planas próximas ao leito dos rios, caracterizada pelo leito superior do rio, portanto áreas suscetíveis a inundações.

Representando $472,06 \mathrm{~km}^{2}$ da área de estudo, ou seja, $20,19 \%$, as declividades de 2 á $5 \%$ é a segunda maior classe presente no município. Está presente em quase toda a extensão da área de estudo, mas destacando-se nas áreas de Sudoeste e o Setor Oeste. Estão relacionadas às pequenas elevações presentes no município onde são as cabeceiras dos rios.

Em uma área total de 468,92 $\mathrm{km}^{2}$, representando $20 \%$ da área de estudo, as declividades de 5 a 15\% estão associadas às cabeceiras de rios, assim como as declivi-

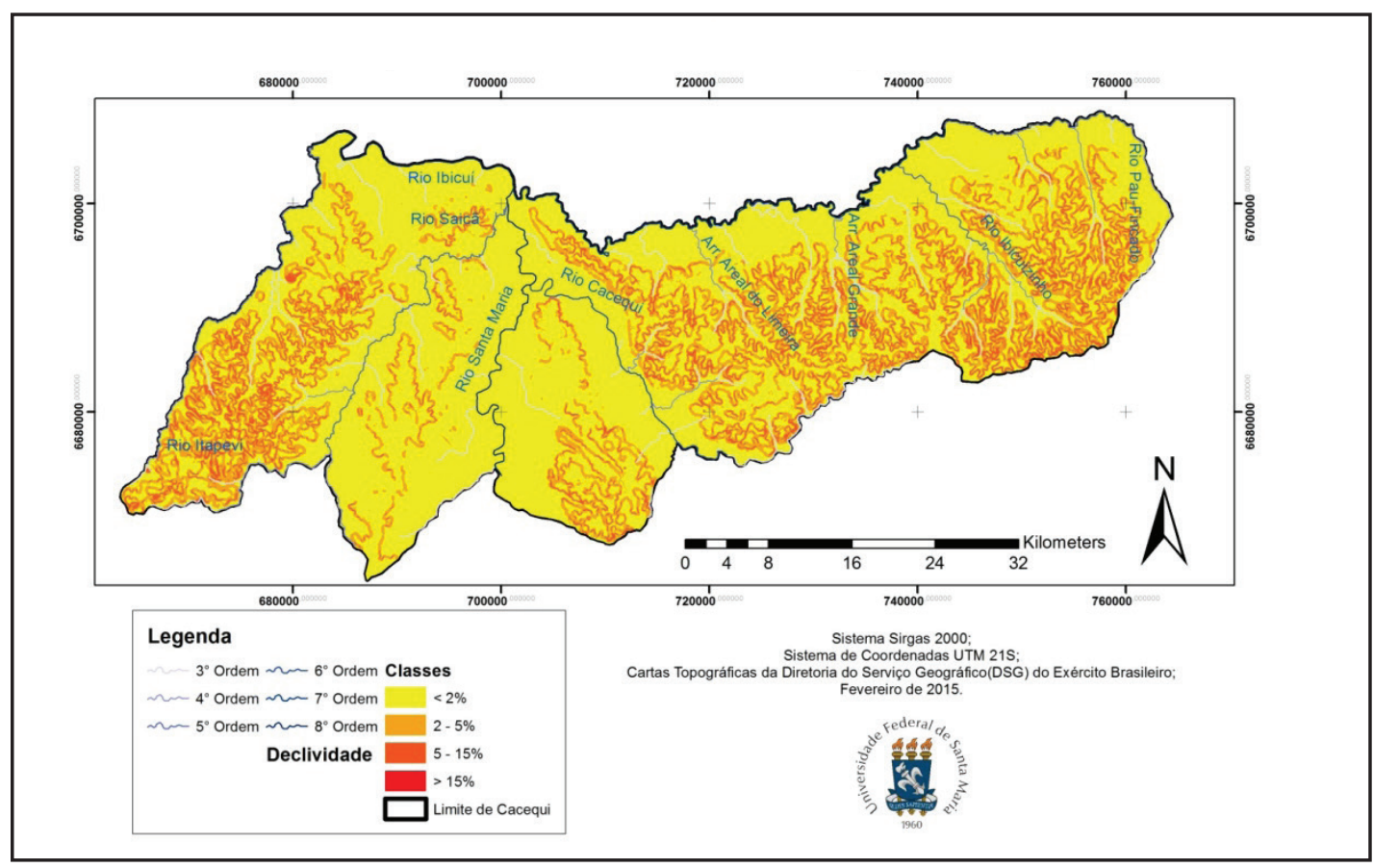

Figura 6 - Mapa de declividade do Município de Cacequi - RS

Org: Os Autores, 2015 
dades de 2 á 5\%, majoritariamente na região Sudoeste e o Setor Oeste.

E presente em 1,55\% do município as declividades maiores de $15 \%$ representam $36,45 \mathrm{~km}^{2}$. Estas áreas estão associadas aos picos das elevações no terreno do município ou na maior parte às encostas dos morros e morrotes presentes no município.

Sendo assim, devido à baixa amplitude altimétrica do município também há pouca declividade, sendo uma área bastante plana e de ambiente sedimentar, Cacequi têm seu aspecto de relevo plano com declividades significativas apenas nas porções de morrotes presentes no município, constituindo as vertentes do terço superior. Observa-se então que é um local onde a superfície do terreno é bastante homogênea, com pequenas variações de altimetria e de declividade, facilitando o uso de maquinário agrícola e também se tornando uma área propícia para a pecuária, o que acaba refletindo no uso e a ocupação do solo em Cacequi.

\subsection{Análise do Comprimento Médio das Ver- tentes}

De acordo com a análise do comprimento das vertentes no município de Cacequi, observou-se uma grande homogeneidade, com uma média geral de 1,19 $\mathrm{km}$ de comprimento na área de estudo.

Porém, mesmo com uma homogeneidade grande há uma diferença dentro das sub-bacias da área de estudo. Conclui-se que nas bacias onde há uma maior amplitude altimétrica as vertentes são menores, com um relevo um pouco mais acidentado. Observa-se que nas regiões planas como nas sub-bacias do Rio Santa Maria, Itapevi, Saicã e Pau-Fincado as vertentes são mais longas. E em outras sub-bacias como Santa Catarina e Ibicuízinho onde há uma variação maior de altitude e declividade têm vertentes mais curtas, como mostra a tabela 4 , a seguir.
A Tabela 4 apresenta que é muito semelhante os valores de comprimento de vertente em todas as Sub-Bacias, observando que a diferença entre a maior média e a menor é de apenas 630 metros e que o comprimento médio das vertentes do local apresenta um desvio padrão de 1,09 $\mathrm{km}$. Também, conclui-se que os maiores comprimentos de vertentes estão nas áreas de baixas altitudes do município, nas sub-bacias Pau-Fincado e Itapevi. Já as vertentes mais curtas localizam-se nas sub-bacias dos rios Ibicuízinho e Santa Catarina.

\section{Análise de Formas de Relevo}

Ao longo do território do município de Cacequi, foram definidas quatro formas de relevo distintas, Colinas Suaves, Colinas, Morrotes e Planícies, conforme o mapa da figura 7.

Analisando o mapa, conclui-se que Cacequi tem colinas (Figura 8) em 53,9\% de seu território, ou seja, $1261,83 \mathrm{~km}^{2}$, portanto a forma de relevo mais presente no local. Estas colinas constituem principalmente as cabeceiras de rios e áreas drenadas por rios intermitentes e de ordens pequenas. Coincidem também com as áreas de declividades de 5 á 15\% e com altitudes de 110 até 170 metros, presentes em sua maior parte no setor Leste do município, sendo que estas colinas são as cabeceiras dos rios deste setor, e também presente em parte do setor Centro-Oeste, predominantemente nas partes altas das sub-bacias dos rios Itapevi e Saicã.

.A segunda forma de relevo que mais se apresenta no local de estudo são as planícies, que representam 39,9\% da área total, num total de $934,64 \mathrm{~km}^{2}$. As planícies estão localizadas próximas ao leito dos rios principais de cada bacia, caracterizadas por locais de baixa altitude, predominantemente de 80 á 110 metros e de declividades inferiores o $2 \%$. São áreas suscetíveis a inundação por serem muito planas e próximas a canais de volume de

Tabela 4 - Comprimento Médio das vertentes de Cada Sub-Bacia de Cacequi

\begin{tabular}{cc}
\hline Sub-Bacia & Comprimento Médio das Vertentes $\mathbf{( k m )}$ \\
Areal do Limeira & 1,13 \\
Areal Grande & 1,32 \\
Cacequi & 1,05 \\
Ibicuí & 1,13 \\
Ibicuízinho & 1,01 \\
Itapevi & 1,38 \\
Pau Fincado & 1,62 \\
Saicã & 1,15 \\
Santa Catarina & 0,99 \\
Santa Maria & 1,21 \\
\hline
\end{tabular}

Org: Os Autores 2015 


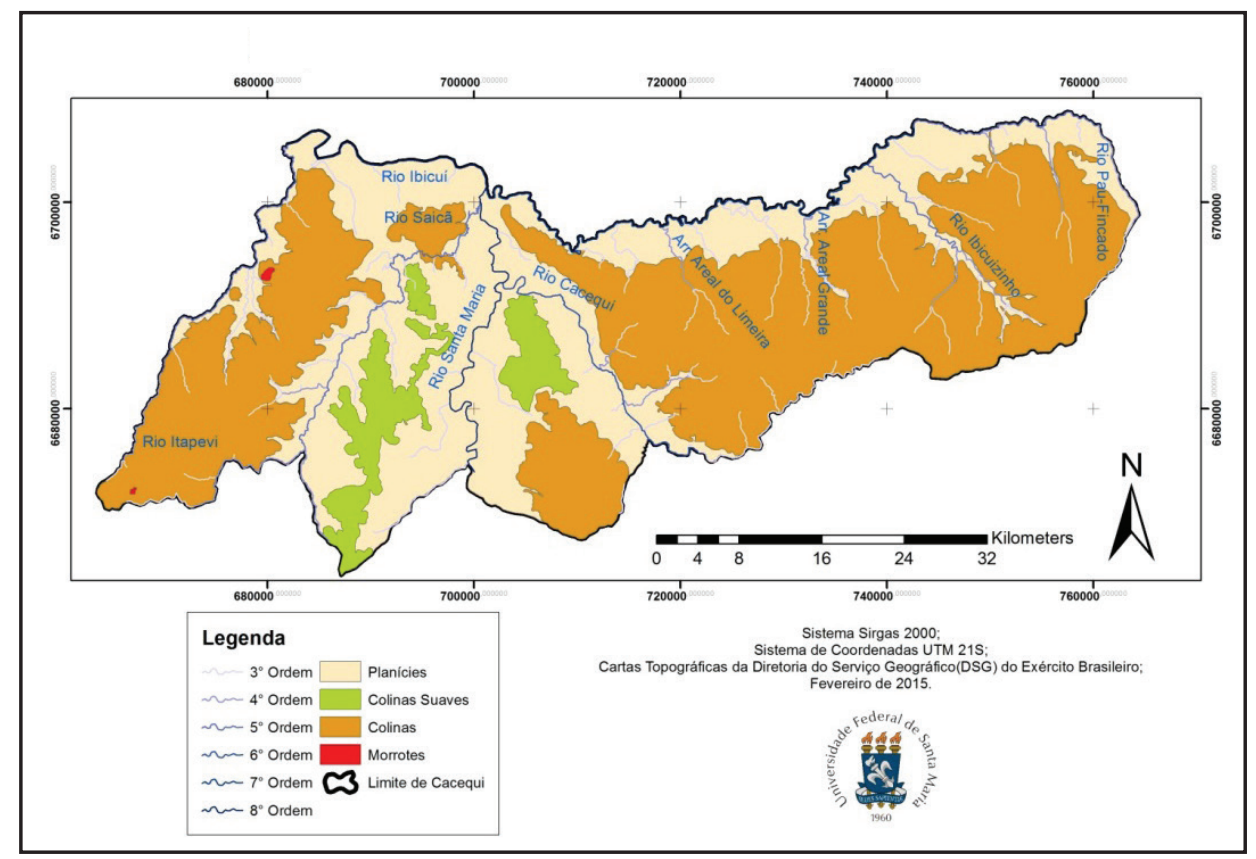

Figura 7 - Mapa de Formas de Relevo do Município de Cacequi- RS Org: Os Autores, 2015

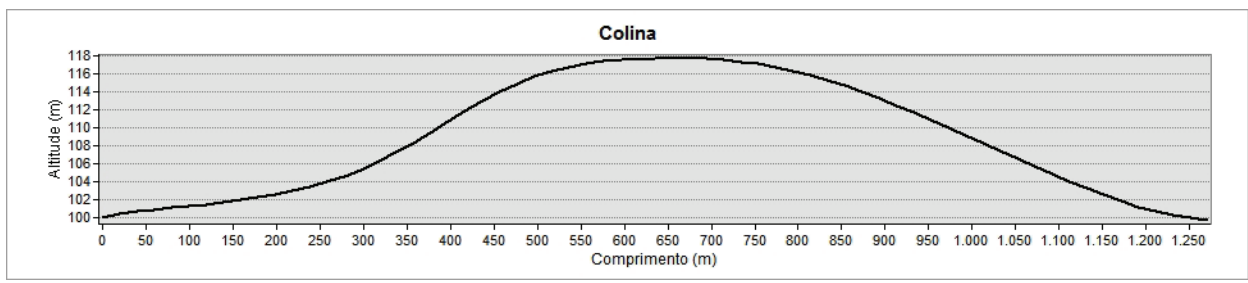

Figura 8 - Perfil Topográfico de uma Colina no Município de Cacequi - RS

Org: Os Autores, 2015

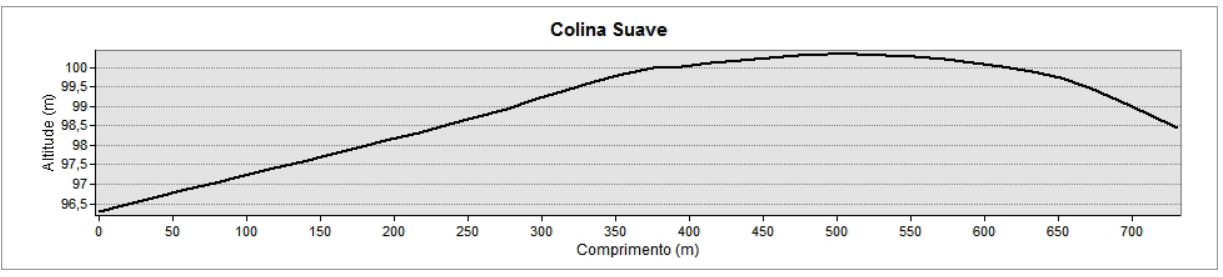

Figura 9 - Perfil Topográfico de uma Colina Suave no Município de Cacequi - RS

Org: Os Autores, 2015

água significativo. Está em quase toda a extensão do município, mas mais frequente no setor Norte próximo ao rio Ibicuí, e também próximo aos rios Santa Maria, Cacequi, Saicã e Ibicuízinho.

Em 5,6\% da área de estudo, ou seja, $131,15 \mathrm{~km}^{2}$ há feições de colinas suaves, representado na Figura 9, com altitudes médias de 110 á 140 metros, e declividades de 2 até $5 \%$, estão todas no setor Centro-Oeste de Cacequi, caracterizando o divisor de águas das sub-bacias mais baixas da área de estudo, do rio Saicã e Santa Maria e também no divisor das sub-bacias dos rios Santa Maria e Cacequi.

Em menos de $1 \%$ do território, aproximadamente
0,5\%, o relevo apresenta feições de morrotes. Em apenas $11,05 \mathrm{~km}^{2}$ do território, são morros isolados e cabeceiras de alguns canais de pequena ordem. Estão no setor Centro-Oeste do local de análise, chegando a altitudes superiores a 170 metros e em alguns pontos declividades maiores que $15 \%$, caracterizada também por ser uma área onde ocorrem processos erosivos mais acentuados.

No município de Cacequi distinguem-se um relevo formado de colinas, colinas suaves e morrotes, caracterizado pelas cabeceiras das sub-bacias, e as áreas de menor altitude são áreas bastante planas caracterizadas pela planície de inundação dos rios principais do município. 


\section{Considerações Finais}

A análise do relevo de Cacequi se deu de forma eficaz, visto que se obtiveram resultados significativos da análise hipsométrica, de declividade, comprimento das vertentes, hidrografia e também formas de relevo. Através do uso dos SIGs foi feita a espacialização e análises quantitativas dos dados, e após isto uma análise qualitativa e descrição das características do relevo de Cacequi.

Observou-se que Cacequi possui altitude baixa e também pequena variação da mesma, de apenas 145 metros, consequentemente apresenta declividades baixas ao longo do município, caracterizando um relevo bastante homogêneo representado pelos valores muito próximos de comprimento médio das vertentes em suas sub-bacias. Assim, de acordo com estes dados foi analisado e discriminado quatro tipos de formas de relevo na área de estudo, predominando colinas e planícies.

Assim, sendo que a hidrografia se comporta de acordo com o relevo, tem-se no município de Cacequi uma densidade de drenagem baixa, pois o relevo bastante plano facilita a infiltração da água no solo, ainda com o agravante da litologia local, sendo ela de ambiente sedimentar. Quanto ao padrão de drenagem, há uma drenagem de característica mais dendrítica nas áreas de planície e paralelas nos sulcos formados nas colinas e morrotes. Como o município possui drenagens de grande ordem, com grande volume de água e áreas planas é bastante suscetível a inundações.

Conclui-se que Cacequi possui um relevo bastante baixo e com pequenas declividades, o que proporciona para a drenagem da região grandes planícies de inundação, e abre espaço para a análise litológica do local para obter mais dados da região e sua influência no relevo e na ocupação do local.

Portanto, o estudo do relevo e da drenagem do município se mostra de caráter importante para a análise geoambiental e geomorfológica, podendo ser utilizado para gestão do município, e planejamento da área, também pode ser utilizado de subsídio para novos estudos da região.

\section{Agradecimentos}

Os autores agradecem à UFSM e CNPq, pelo apoio financeiro.

\section{Referências}

BARATTO, D. S.; TRENTIN, R.; Análise das Unidades de Relevo da bacia Hidrográfica do Arroio Puitã (RS). Revista Geonorte, Edição Especial, V.3, N.4, p. 543-555, 2012.

CHRISTOFOLETTI, A. A variabilidade espacial e temporal da densidade de drenagem. Notícia
Geomorfológica, v.21, n.42, p. 3-22, 1981

Geomorfologia. São Paulo: Universidade de São Paulo, 1974.

. Geomorfologia fluvial. São Paulo: Edgard Blucher, 1981.

DE NARDIN, D.; ROBAINA, L. E. D. S. Mapeamento de Unidades do Relevo no Oeste do RS: O Caso da Bacia Hidrográfica do Arroio Miracatú. Anais do XI Simpósio Brasileiro de Geografia Física Aplicada, São Paulo, 2005.

Instituto Brasileiro de Geografia (IBGE). Malha municipal digital. Disponível em: ftp://geoftp.ibge.gov.br/mapas/ malhas_digitais/municipio_2010/

MENEZES et al.; Mapeamento de uso da Terra do Munícipio de São Pedro do Sul - RS. XV Simpósio Brasileira de Geografia Física Aplicada, Vitória, ES, 2013.

TRENTIN, R; ROBAINA, L. E. S.; Mapeamento Morfolitológico da Bacia Hidrográfica do Rio Itú. VI Simpósio Nacional de Geomorfologia. Goiânia-GO, 2006. Universidade Federal de Santa Maria.

SOARES, M. R. G. J; SOUZA J. L. M.; Análise Morfométrica da Bacia Hidrográfica do Rio Pequeno em São José dos Pinhais (PR). Revista Geografia: Londrina, v. 21, n. 1, p. 019 - 036, jan/abr, 2012.

STRAHLER, A. N. Hypsometric (area-altitude) analysis of erosional topography. Geological Society of America Bulletin, 1952.Vol. 63, p. 1117-1142.

VILLELA, J. V.; MATTOS, A. Hidrologia Aplicada. São Paulo: McGraw-Hil do Brasil, 1975. 